\title{
Geriatric Medicine and Gerontology
}

RESEARCH ARTICLE

\section{The Relationship between Foot Care Behaviors and Metabolic Control Criteria of the Elderly with Diabetes}

\author{
Sümeyra Mihrap ILTER ${ }^{1 *}$, Özlem OVAYOLU² and Nimet OVAYOLU³ \\ ${ }^{1}$ Department of Nursing, School of Health, Kahramanmaraş Sütçü Imam University, Afşin, Turkey \\ ${ }^{2}$ Department of Nursing, Faculty of Health Science, Gaziantep University, Gaziantep, Turkey \\ ${ }^{3}$ Department of Nursing, University of Kyrenia, Cyprus, Cyprus
}

*Corresponding author: Sümeyra Mihrap ILTER, Department of Nursing, School of Health, Kahramanmaraş Sütçü Imam University, Afşin, Turkey

\begin{abstract}
Purpose: The aim of this study is to investigate the relationship between foot care behaviors and metabolic control parameters of the elderly individuals diagnosed with diabetes.

Methods: The study was carried out as a descriptive study in a training and research hospital between February and July 2017 . The study was conducted with patients diagnosed with diabetes. Data of the research; the questionary form was obtained with some laboratory results from the foot care scale (FCS) and patient records.

Results: This study was completed with 135 patients. The diabetic foot care scale mean score of the patients was 45.8 \pm 8.9 and the mean of metabolic control values was high $\mathrm{HbA} 1 \mathrm{c}$, fasting blood glucose, waist circumference, body mass index, triglyceride score averages, diabetic foot care scale mean score was found to decrease.

Conclusion: In this study, it was found that there was a relation between the metabolic control criteria of the elderly individuals and the mean score of diabetic foot care scale, and the mean score of diabetic foot care scale was lower in the patients who did not have enough metabolic control. For this reason, it may be suggested to give training for patients to provide metabolic control and to prevent complications.
\end{abstract}

\section{Keywords}

Geriatrics, Diabetic foot, Metabolic control, Nursing

\section{Introduction}

Today, diabetes is an increasingly important health problem in the world due to its incidence and the problems it creates. With lifestyle changes, the prevalence of type 2 diabetes is increasing rapidly in all developed and developing societies, and it is estimated that 642 million people will be diagnosed with diabetes in 2040 [1,2]. The prevalence of diabetes, especially with the prolongation of life expectancy, is higher in the population over 65 years of age. In our country, According to the results of Turkey Diabetes, Hypertension, Obesity and Endocrinology Diseases Prevalence Study II (TURDEP II), people over the age of 65 were reported to have $34.8 \%$ prevalence of diabetes $[3,4]$. As it is known, fasting plasma glucose level increases by $2 \mathrm{mg} / \mathrm{dl}$ every 10 years in normal aging. Beta cell function is impaired due to reasons such as; increase in weight, decrease in muscle mass and increase insulin resistance. In addition, other diseases associated with the elderly, reduced activity and drug use also increase insulin resistance. Due to all these changes, the incidence of diabetes and complication rate in elderly individuals increases $3-4 \mathrm{mg} /$ dl $[3,4]$. In addition, $46 \%$ of diabetic patients are not aware of the fact that they are diabetic and are at serious risk in terms of acute/chronic complications related to diabetes [5]. Especially, complications such as retinopathy, nephropathy, and neuropathy $[6,7]$ may cause high mortality and morbidity, leading to job loss and economic and social problems [7].

Nerve damage in the neuropathy and the organ that is most affected by ischemic vascular disease are the lower extremities of people with diabetes. Diabetic angiopathy, which develops in the course of 
diabetes, and irregular glucose regulation are considered to be responsible for the occurrence of complications such as neuropathy [8]. It is known that various changes in metabolic control criteria, particularly lipids in diabetes, provide a basis for the development of complications, cause damage to peripheral myelinated neurons and intermolecular impulse transmission disorders among neurons [9-15]. However, diabetic neuropathy and diabetic foot, which is a follow up, are controllable and preventable health problems [7-12]. On the other hand, in many studies, it was concluded that foot health information and foot care behaviors of people with diabetes are insufficient [16-20]. However, gaining self-efficacy behaviors for diabetic individuals can reduce and prevent the complications such as neuropathy and diabetic foot, and provide the metabolic control values at safe intervals [13-17]. Therefore, it is very important for individuals with diabetes to have sufficient knowledge about the metabolic control values and foot care, and to convert this information into behavior. Especially the protection of foot health in the elderly increases the quality of life of the individual and provides the continuity of walking ability. In this context, it is very important to examine the metabolic control values and foot care behaviors of the patients with diabetes in terms of the desired foot care behaviors practices in order to provide diabetes management, maintain the metabolic control values at optimal intervals [18-22]. The aim of this study is to investigate the relationship between metabolic control parameters and diabetic foot care behaviors of elderly people diagnosed with diabetes and to make recommendations to the health professionals who follow these patients in clinics.

\section{Materials and Method}

The study was carried out between February and July 2017 in a Training and Research Hospital, Internal Medicine, Endocrinology and Metabolic Diseases Policlinic. Prior to the study, the permit was obtained from the ethics committee, institution and patients who were informed about the purpose of the study and the content of the questionnaires. The study population consisted of all patients who were admitted to the clinic for treatment on the dates specified. The required number of patients whom the samples were taken was calculated $(\alpha=0.05$ and strength of test $=0.80$ ) in minimum 61 , by considering the analysis of the study [23], with the highest sampling and using appropriate statistical methods according to the opinions of the experts in the field to find a weak significant correlation $(r=0.35)$ between the correlation analysis scale and the clinical variables, the study was completed by reaching 135 patients.

\section{Inclusion criteria}

Patients aged 65 years and over, who were diag- nosed with diabetes, were able to communicate, were rated as 24 and above from the mini-mental test, had no bilateral foot amputation and who accepted to participate in the research were included in the study.

\section{Data collection process}

'Questionary form' and 'Foot Care Behavior Scale' including socio-demographic, diabetes and metabolic control values were used for data collection.

\section{Questionary form}

In this form, questions related to gender, age, education, antidiabetic treatment, diabetes training, eye, heart and nephrology examination were included. Data on the metabolic control values of patients including diabetes, $\mathrm{HbA1C}, \mathrm{HDL}$, triglyceride and fasting blood glucose were obtained from the patient records. The metabolic control parameters to avoid the complications of diabetes and to manage them must be as follows: fasting blood glucose $<126 \mathrm{mg} /$ $\mathrm{dL}, \mathrm{HbA} 1 \mathrm{C}$ value $<6.5 \%$, and $\mathrm{HDL}$ value $<40$.

Body Mass Index: It was determined by dividing the square of the height of the body $\left(\mathrm{m}^{2}\right)$ by the body weight (kg), the evaluation: 0 - 18.4: Slim, 18.5 - 24.9: Normal, 25.0 - 29.9: Overweight, 30.0 - 34.9: Obese - I. Class, 35.0 - 44.9: Obese (Obese) - II. Class, 45.0 and above: Overweight (Excessive Obese) - III. The International Diabetes Association (IDF) associated central obesity with waist circumference being $\geq 94$ $\mathrm{cm}$ in males and $\geq 80 \mathrm{~cm}$ in females. Individuals must be below these values to prevent the diabetes and its complications [24-27].

\section{Foot care behavior scale}

This scale was developed by Borges in 2007 in accordance with the criteria of American Diabetes Association (ADA) in order to develop foot self-care behaviors [28]. The validity and reliability of the Turkish version of the scale was performed by Enç and Biçer in 2008 [29] and consisted of five sub-dimensional fifteen questions about diabetic foot care. The highest score for this scale is 75 , and the lowest score is 15 , the high score indicates 'adequate foot care', while the low score indicates 'insufficient foot care' behaviors.

\section{Data analysis}

The findings of the study were evaluated by student $t$, one way anova, correlation analysis in electronic environment $p<0.05$ was considered statistically significant.

\section{Results}

It was determined that $56.3 \%$ of the patients were female and $77 \%$ were primary school graduates, $73.2 \%$ of them received oral antidiabetic (OAD) and insulin therapy and $62.2 \%$ of them received diabetes training. It was stated that $46.7 \%$ of the elderly people with di- 
Table 1: Some characteristics of patients and Foot Care Behavior Scale Score Mean.

\begin{tabular}{|c|c|c|c|}
\hline Characteristics & $\begin{array}{l}n(\%) \\
X \pm S D\end{array}$ & Diabetic Foot Care Scala & $\mathbf{p}$ \\
\hline \multicolumn{4}{|l|}{ Gender } \\
\hline Female & $76(56.3)$ & $45.88 \pm 9.17$ & \multirow[t]{2}{*}{0.894} \\
\hline Male & $59(43.7)$ & $45.86 \pm 8.57$ & \\
\hline \multicolumn{4}{|l|}{ Age } \\
\hline $65-70$ & $88(65.2)$ & $45.25 \pm 9.250$ & \multirow[t]{3}{*}{0.295} \\
\hline $71-76$ & $40(29.6)$ & $47.72 \pm 8.26$ & \\
\hline $77-82$ & $7(5.2)$ & $45.57 \pm 8.36$ & \\
\hline \multicolumn{4}{|l|}{ Education } \\
\hline Primary School & $104(77.0)$ & $45.56 \pm 8.56$ & \multirow[t]{2}{*}{0.509} \\
\hline High School & $31(23.0)$ & $46.90 \pm 10.13$ & \\
\hline \multicolumn{4}{|l|}{ Treatment } \\
\hline Insulin & $32(23.70)$ & $47.75 \pm 9.76$ & \multirow[t]{3}{*}{0.042} \\
\hline $\mathrm{OAD}^{*}$ & $23(17.03)$ & $54.67 \pm 6.14$ & \\
\hline OAD + insulin & $80(59.27)$ & $46.32 \pm 7.66$ & \\
\hline \multicolumn{4}{|l|}{ Diabetes Training } \\
\hline Yes & $84(62.2)$ & $45.07 \pm 7.38$ & \multirow[t]{2}{*}{0.000} \\
\hline No & $51(37.7)$ & $46.93 \pm 9.65$ & \\
\hline \multicolumn{4}{|l|}{ Eye Examination } \\
\hline Yes & $63(46.70)$ & $45.95 \pm 8.90$ & \multirow[t]{2}{*}{0.625} \\
\hline No & $72(53.30)$ & $45.80 \pm 9.04$ & \\
\hline \multicolumn{4}{|l|}{ Heart Examination } \\
\hline Yes & $109(80.7)$ & $44.88 \pm 8.84$ & \multirow[t]{2}{*}{0.008} \\
\hline No & $26(19.3)$ & $50.00 \pm 8.31$ & \\
\hline \multicolumn{4}{|c|}{ Nephrology Examination } \\
\hline Yes & $25(16.2)$ & $47.28 \pm 9.54$ & \multirow[t]{2}{*}{0.051} \\
\hline No & $110(83.7)$ & $44.25 \pm 8.06$ & \\
\hline \multicolumn{4}{|l|}{ Foot Examination } \\
\hline Yes & $76(56.3)$ & $51.55 \pm 6.77$ & \multirow[t]{2}{*}{0.000} \\
\hline No & $59(43.7)$ & $38.55 \pm 5.37$ & \\
\hline Scale Score Mean & & $45.80 \pm 8.90$ & \\
\hline
\end{tabular}

*OAD: Oral Antidiabetic.

abetes diagnosis had eye, $80.7 \%$ cardiology and $56.3 \%$ foot examination.

While the mean score of the foot care scale was found to be $45.8 \pm 8.9$, it was determined that there was no significant relationship between gender $(p=$ $0.894)$, age $(p=0.295)$, educational level $(p=0.509)$ and socio-demographic characteristics and foot care scale. It was found that there was a significant relationship among diabetes treatment $(p=0.000)$, diabetes training status $(p=0.000)$, heart examination ( $p$ $=0.008)$, foot examination status $(p=0.000)$ and foot care behavior. No significant relationship was found among eye examination ( $p=0.625$ ) and renal examination $(p=0.051)$ and foot care behaviors (Table 1$)$.

Metabolic control parameters means of patients was determined as $\mathrm{HbA} 1 \mathrm{c} ; 8.4 \pm 1.0$, fasting blood
Table 2: Distribution of Metabolic Control Values Mean of Patients.

\begin{tabular}{|l|l|}
\hline Characteristics & $\mathbf{X} \pm$ SD \\
\hline HbA1C & $8.4 \pm 1.0$ \\
\hline Fasting Blood Glucose & $136 \pm 10.1$ \\
\hline HDL & $39.7 \pm 4.2$ \\
\hline Triglyceride & $203.5 \pm 14.8$ \\
\hline Waist Circumference & $103.3 \pm 10.8$ \\
\hline "BMI & $24.81 \pm 2.1$ \\
\hline
\end{tabular}

*BMI: Body Mass Index.

glucose; $136 \pm 10.1$, triglyceride; $203.5 \pm 14.8$, body mass index; $103.3 \pm 10.8$, waist circumference 24.5 \pm 2.1 (Table 2). A negative correlation was found among $\mathrm{HbA1C}$, fasting blood glucose, HDL, triglycer- 
Table 3: Relationship between Metabolic Control Criteria and Diabetic Foot Care Behavior Scale.

\begin{tabular}{|l|l|l|}
\hline Characteristics & r & p \\
\hline HbA1C & -0.075 & 0.137 \\
\hline Fasting Blood Glucose & -0.158 & 0.067 \\
\hline HDL & -0.802 & 0.346 \\
\hline Triglyceride & -0.011 & 0.014 \\
\hline Waist Circumference & -0.089 & 0.307 \\
\hline
\end{tabular}

ide, waist circumference, and foot care scale mean scores (Table 3).

\section{Discussion}

With increasing life expectancy, diabetes is becoming increasingly widespread. Especially in the elderly individuals with diabetes diagnosis, when the complications and cost are considered, diabetes appears as an important health problem [19-22,30]. Accordingly in this study, it has been aimed to determine the relationship between foot care behaviors and metabolic control values of elderly people with diabetes, and to prevent the foot complications that may develop and to create awareness about this issue.

Since the elderly individuals with diabetes are at risk for microvascular and macrovascular complications of diabetes, it is very important to scan them in terms of complications. The multidisciplinary follow-up of elderly individuals with diabetes, especially by cardiology, nephrology, neurology and ophthalmology units is of great importance for the prevention and management of possible complications [16,21,30-34]. Because, in this study, it has been stated that many chronic complications such as diabetic foot wound, hypertension, retinopathy and neuropathy develop in patients $[35,36]$. However, the majority of the patients in our study stated that they did not have eye and kidney health checks, yet that they had their cardiology and foot examination. As it is known, while the annual incidence of diabetic foot ulcers varies between 1-4\% [37], approximately $50 \%$ of non-traumatic lower extremity amputations constitute diabetic patients [38]. However, diabetic foot, which may result in loss of limb, is a preventable complication with regular control and training.

Most of the patients included in the study stated that they received training on diabetes. Similarly, in the study of Yanık and Erol, the majority of the individuals diagnosed with diabetes stated that they had received training about the disease and turned the content of training into behavior [16]. However, in the study of Akaltun and Ersin, the majority of the patients stated that they did not receive any education about diabetes [39]. It can be said that this situation poses a risk in terms of the complication rate related to diabetes, and therefore, whole health team have serious responsibilities, especially the diabetes training nurses.
Providing metabolic control in diabetic patients is extremely important for preventing the development of unwanted side-effects. Since in the literature, it is stated that the quality of life is worse in patients with insufficient metabolic control and these patients have more likely to lose some of their abilities [1822]. In the study carried out by Lee, et al. it was found that $68.6 \%$ of the patients and in the study of Gao, et al. $47.3 \%$ of the patients had $\mathrm{HbA1c}$ value above the optimal limit $[32,33]$. In addition, in other studies conducted in this area, the metabolic control values of the individuals diagnosed with diabetes were found to higher than the reference range in parallel with our study results [34,35]. However, it has been shown that when the glycemic control and $\mathrm{HbA1c}$ values are $<7 \%$, complications are to reduce significantly [40]. In this respect, it should be remembered that metabolic control values in the appropriate reference range especially in elderly individuals with diabetes have a guiding role in the course of the disease and complications. Therefore, metabolic control values should be followed up regularly in all people with diabetes.

Diabetic foot, which is one of the most important complications of diabetes, is caused both by diabetes and the wrong behaviors of the person for the foot care. In studies conducted, it was determined that patients' behaviors towards diabetic foot care were insufficient, and neuropathy and diabetic foot ulcer development were directly related to foot care behaviors [41-43]. In a study conducted by Policarpo, et al. it has been found that most of the patients do not know the foot care hygiene practices, and Rao Lie, et al. $[41,44]$ reports that the training about the diabetic foot care of the patients is insufficient. Erkoç, et al. in their study with nursing home inhabitants, it has been stated that the elderly people wash their feet using warm water, towel their feet and toe-webs after each wash, examine their feet by themselves, cut their fingernails firmly without waiting them to grow, wear appropriate quality of socks and shoes [45]. In a study carried out by Nural and Hindistan, it was determined that patients had a lack of information about foot care, had practices which could lead to foot ulcers and that their glycemic levels were above the targeted values [23]. In our study, it was determined that the mean score of the diabetic foot care behaviors of the elderly individuals was at 'moderate level'. In the light of this information, it is considered that an effective diabetes management may prevent or manage many complications in individuals with the diabetes diagnosis $[14,38,39,41,46]$.

\section{Conclusion}

It was stated that the mean score of the diabetic foot care scale of the elderly was moderate and a negative correlation was found between the metabolic control criteria and the mean score of diabetic 
foot care scale. Therefore, especially monitoring the elderly regularly, supporting and developing their awareness by providing training can be suggested in terms of effective diabetes management, chronic complications particularly diabetic foot prevention, and management.

\section{References}

1. Coşansu G (2015) Diabetes: A Global Epidemic. Okmeydanı Faculty of Medicine 31: 1-6.

2. Choac NH, SnawbS JE, Karurangaa Y, Huanga JD da, Rocha Fernandesa AW, et al. (2017) Diabetes Atlas. ( $7^{\text {th }}$ edn)

3. Satman I, Omer B, Tutuncu Y, Kalaca S, Gedik S, et al (2013) Twelve-Year Trends in the Prevelance and Risk Factors of Diabetes and Prediabetes in Turkısh Adults. Eur J Epidemiol 28: 169-180.

4. Ligthelm RJ, Kaiser M, Vora J, Yale JF (2012) Insulin use in elderly adults: Risk of hypoglycemia and strategy for care. J Am Geriatr Soc 60: 1564-1570.

5. Plantinga LC, Crews DC, Coresh J, Miller ER, Saran R, et al. (2010) Prevalence of chronic kidney disease in US adults with undiagnosed diabetes or prediabetes. Clin J Am Soc Nephrol 5: 673-682.

6. Şensoy N, Gençoğlan G (2009) Relation between skin findings and body mass index and $\mathrm{HbA} 1 \mathrm{c}$ in Type II diabetes patients. Anatol J Clin Investig, 213-217.

7. Günal $A$, Başkurt $F$, Başkurt Z, Parpucu IT, Yücekaya $B$ (2012) Examining the relation between obstacle perception and functional incapability in elderly Type- II Diabetes patients, S.D.U. Health Institute Journal 3: 31-33.

8. Uygar U (2015) Peripheric and Cranial Neuropathies. KSU, Faculty of Medicine Journal 10: 49-51.

9. Powers AC (2001) Diabetes mellitus. In: Kasper DL, Braunwald E, Fauci AS, Hauser SL, Longo DL, et al. Harrison's Principles of Internal Medicine. (15 ${ }^{\text {th }}$ edn), McGraw-Hill, New York,USA, 2109-2138.

10. Batkın D, Çetinkaya F (2005) Knowledge, attitude and behaviors of diabetes mellitus patients on foot care and diabetic foot. Health Sciences Journal, 6-12.

11. Bölükbaş N, Paydaş M, Bostan Ö (2006) Determining the behaviors of patients with diabetes on foot care and current foot status. Firat Health Services Journal 2: 82-91.

12. Aypak C, Koç A, Yıkılkan H, Görpelioğlu S (2012) Diabetic Foot Care: Application status reported by the patients applying to family physician clinics. Cumhuriyet Medical Journal 34: 423-428.

13. Erkoç A, Yürügen B (2008) Diabetik Foot: Case Study. Diabetes Forum 4: 50-56.

14. Corbett CF (2003) A randomized pilot study of improving foot care in home health patients with diabetes. Diabetes Educ 29: 273-282.

15. Mungan ÖS, Şahin S, Kızıltan M (2010) The Relation between Painful Diabetic Neuropathy and Hypertriglyceridemia and Hypercholesterolemia. Turkish Geriatrics Journal 13: 73-77.

16. Yanık YT, Erol Ö (2016) Evaluation of Self-efficacy Levels of Individuals with Type-2 Diabetes. Anadolu Nursing and Health Sciences Journal 19: 166-174.

17. Eren İ, Erdi Ö, Çivi I (2004) Quality of Life in Type-II Diabetes mellitus patients and the effect of complications on quality of life. Clinic Psychiatry 7: 85-94.

18. Tüzün Ç, Tıkız C (2003) Foot Problems in the Elderly. Turkish Journal of Geriatrics 6: 135-141.

19. López-López D, Martínez-Vázquez M, Losa-Iglesias ME, Calvo-Lobo C, Rodríguez-Sanz D, et al. (2018) Foot health-related quality of life among elderly with and without lesser toe deformities: A case-control study. Patient Prefer Adherence 10: 251-255.

20. Menz HB, Lord SR (2001) Foot pain impairs balance and functional ability in community-dwelling older people. J Am Podiatr Med Assoc 91: 222-229.

21. Wells Y (2011) Foot Problems in Older People: Assessment and Management. Australasian Journal on Ageing 30: 48-48.

22. Eskiyurt N (2010) Foot Problems in Older People: Assessment and Management. Turkey Clinics Physical Medicine and Rehabilitation Special Journal 3: 62-68.

23. Nural N, Hindistan S (2015) Examining the Knowledge and Attitudes of Diabetic Patients in Terms of Foot Care. Anadolu Nursing and Health Sciences Journal 18: 116-124.

24. (2019) ATP III Guidelines At-A-Glance Quick Desk Reference. National Cholesterol Education Program NIH Publication.

25. https://www.diabetes.co.uk/newly-diagnosed-with-type2-diabetes.html

26. World Health Organization (2000) Obesity: Preventing and managing the global epidemic.

27. Tsigos C, Hainer V, Basdevant A, Finer N, Fried M, et al. (2008) Management of obesity in adults: European clinical practice guidelines. Obes Facts 1: 106-116.

28. Borges WJ, Ostwald SK (2008) Improving Foot Self-Care Behaviors with PiesSanos. West J Nurs Re 3: 325-341.

29. Biçer E, Enç N (2014) Foot Care Behavior Scale. Turkish Form Validity and Reliability 6: 35-39.

30. Ahmad N, Thomas GN, Gill P, Torella F (2016) The Prevalence of Major Lower Limb Amputation in Diabetic and Non-Diabetic Population of England 2003-2013. Diab Vasc Dis Res 13: 348-353.

31. Perrin BM, Swerrisen H, Payne C (2009) The association between foot-care self-efficacy beliefs And actual foot-care behavior in people with peripheral neuropathy: a cross-sectional study. J Foot Ankle Res 2: 3.

32. Oktay M, Oktay G, Ertekin HY, Sönmez IC, Sönmez FT (2012) Evaluation of metabolic syndrome frequency and components in newly-diagnosed type 2 diabetic patients. Ankara Medical Journal 12: 174-177.

33. Chin YF, Liang J, Wang WS, Hsu BR, Huang TT (2014) The role of foot self-care behavior on developing foot ulcers in diabetic patients with peripheral neuropathy: A prospective study. Int J Nurs Stud 51: 1568-1574.

34. Gao J, Wong J, Zheng P, Haardörfer R, Kegler MC, et al. (2013) Effects of self-care, self-efficacy, social support on glycemic control in adults with type 2 diabetes. BMC Fam Pract 14-66.

35. Lee EH, Bijl J, Baggett LM, Han SJ, Moon SH (2015) Psychometric properties of the diabetes management self-efficacy scale in Korean patients with type 2 diabetes. Int $\mathrm{J}$ Endocrinol 1-9.

36. Erol Ö, Enc N (2011) Hypoglycemia fear and self-efficacy of Turkish patients receiving insulin therapy. Asian Nurs Res 
(Korean Soc Nurs Sci) 5: 222-228.

37. Singh N, Armstrong DG, Lipsky BA (2005) Preventing foot ulcers in patients with diabetes. JAMA 293: 217-218.

38. Reiber GE (2001) Epidemiology of foot ulcers and amputations in the diabetic foot. In: Bowker JH, Pfeifer MA, In The Diabetic Foot. (6 $6^{\text {th }}$ edn), St. Louis, MO, Mosby, 13-32.

39. Akaltun H, Ersin F (2016) Determining the Diabetes Attitudes and Behaviors of Diabetes Patients Receiving Homecare. Dokuz Eylül University, Nursing Faculty, Electronic Journal 9: 126-133.

40. Janka HU, Plewe G, Riddle MC, Kliebe-Frisch C, Schweitzer MA, et al. (2005) Comparison of basal insulin added to oral agents versus twice-daily premixed insulin as initial insulin therapy for type 2 diabetes. Diabetes Care 28: 254259.

41. Li R, Yuan L, Guo XH, Lou QQ, Zhao F, et al. (2014) The current status of foot self-care knowledge, behaviors, and analysis of influencing factors in patients with type 2 diabetes mellitus in China. IJNSS 1: 266-271.
42. Keskin Ö, Balcı M (2011) Diabetes Mellitus and Cardiovascular Complications. Kafkas J Med Sci 1: 81-85.

43. Özkan Y, Çolak R, Demirdağ K, Yıldırım A, Özalp G, et al. (2004) Retrospective evaluation of 142 cases with Diabetic feet syndrome. Turkey Clinics Journal Endocrine 2: 191195.

44. Policarpo NDS, Moura JRA, MeloJunior EBD, Almeida PCD, Macedo SFD, et al. (2014) Knowledge, Attitudes and Practices for the Prevention of Diabetic Foot. Rev Gaucha Enferm 35: 36-42.

45. Erkoç A, Yürügen B, Tan M, Altan E, Malazgirtli I (2015) Foot-care behaviors of the Nursing Home Diabetes Patients, Gümüşhane University. Health Sciences Journal/Gümüşhane University, Journal of Health Sciences 4: 194-203.

46. Alexander CM, Landsman PB, Teutsch SM, Haffner SM, Third National Health and Nutrition Examination Survey (NHANES III), et al. (2003) NCEP defined metabolic syndrome, diabetes, and prevalence of coronary heart disease among NHANES III participants age 50 years and older. Diabetes 52: 1210-1214. 